\title{
Cultural Competence of Nursing Faculty of the LGBT Population
}

\author{
Meriam Caboral-Stevens, PhD, RN, NP-C ${ }^{1 *}$, Maria Rosario-Sim, EdD, PPNP-BC, RNOC ${ }^{2}$, and Keisha \\ Lovence, DNP, ACNP-BC ${ }^{3}$
}

${ }^{1}$ Assistant Professor, School of Nursing, Eastern Michigan University, 310 Marshall Bldg, Ypsilanti, MI, US.

\section{${ }^{2}$ Associate Professor, SUNY Downstate Medical Center,} Brooklyn, NY.

${ }^{3}$ Assistant Professor, School of Nursing, Eastern Michigan University, 310 Marshall Bldg, Ypsilanti, MI, US.

\section{Correspondence:}

Meriam Caboral-Stevens, Assistant Professor, School of Nursing, Eastern Michigan University, 310 Marshall Bldg, Ypsilanti, MI, US, E-mail: msteve37@emich.edu.

Received: 13 April 2018; Accepted: 02 May 2018

Citation: Meriam Caboral-Stevens. Cultural Competence of Nursing Faculty of the LGBT Population. Nur Primary Care. 2018; 2(3): $1-4$.

\section{ABSTRACT}

Background: Evidence suggested that nurse educators were ill-prepared to teach about LGBT. The purpose of this study was to assess cultural competence of nursing faculty of the LGBT population.

Method: A correlational survey design was used. The IAPCC-R was used to assess cultural competence of nursing faculty.

Results: 35 nursing faculty returned the surveys. Cohort consisted of $91 \%$ females, mean age was 51.5 ( \pm 12.5$)$ years, majority were married with $13 \pm 12$ years of teaching experience. The mean score on the IAPCC-R survey was $53 \pm 8$, indicating that nursing faculty were culturally aware of the LGBT. Of the five constructs of cultural competence, cultural desire was the lowest score. A negative correlation between years of experience and IAPCC-R was also found.

Conclusion: Findings showed that nursing faculty are culturally aware of the LGBT population. This study was one of the first quantitative studies that examined cultural competence of nursing faculty.

\section{Keywords}

Nursing faculty, Cultural competency, LGBT population.

\section{Introduction}

Cultural Competence of Nursing Faculty on the LGBT Population There is an estimated 10.1 million adults in the United States (US) who identify as lesbian, gay, bisexual, or transgender (LGBT) [1]. This number is under-represented because of the stigma that goes with this gender identity. The terms lesbian, gay and bisexual denote sexual orientation; whereas transgender refers to someone's gender expression or gender identity. The LGBT community represents a distinct multidimensional group of individuals with unique identities, experiences, and needs. One commonality experienced across all LGBT is their marginalized social status relative to what is normal or traditional gender roles and expectations. Because of this, the LGBT community are subject to stigma, stereotypes, discrimination, and violence. This inequality extends with their experience with healthcare providers, which cause them to avoid or delay seeking help that subsequently affects their overall health status. Several such barriers were identified that contributed to the health disparities within the LGBT community.

One significant barrier is the lack of culturally competent health providers to care for the LGBT community $[2,3]$. The lack of training among the healthcare workforce leads to culturally insensitive environment, further contributing to minority stress felt by the LGBT community. One recommended strategy is to increase knowledge and improve attitudes among the healthcare workforce by providing a strong foundation in their education and training. There are evidence suggesting suggest that the current health curriculum lacks LGBT-specific content studied the undergraduate medical curriculum and found that a median time of 5 hours was devoted on LGBT-content across the 4-year curriculum [5-7]. Similarly in the nursing curriculum, nursing faculty reported that they devoted only $2 \frac{1}{2}$ hours teaching on LGBT health [6]. A recent review of the literature reported that globally, time allotted for 
training on LGBT or LGBT-related issues ranged from one hour to 42 hours [8]. These findings clearly illustrate the lack of education and training on LGBT care among the future healthcare workforce. Some identified reasons for the omissions in nursing is that nurse educators are not prepared to teach the topic and they are unsure how to place LGBT-specific context into their curriculum [5,9]. The purposes of this study were to 1) assess knowledge, attitudes and cultural competence of nursing faculty on LGBT population and 2) determine the relationships between these variables.

\section{Review of the Literature}

Review of the literature noted paucity of research looking at the knowledge, attitudes, and cultural competence of nursing faculty on LGBT issues. To date, only two studies were found in the literature evaluating knowledge, attitudes, and cultural competence of nursing faculty to teach LGBT care. The earlier study by Sirota noted that nurse educators generally have positive attitudes about homosexuality and that it is important to teach students on the topic [9].

However, $72 \%$ of the nurse educators in the study expressed being ill-prepared to teach the topic. A more recent national survey by Lim et al. of nursing faculty teaching in the baccalaureate nursing programs assessed their knowledge and readiness to teach LGBT health [6]. Their study found that nursing faculty has limited knowledge, experience and readiness to teach LGBT. The study also identified some facilitators and barriers in the integration of LGBT health in four areas: the curriculum, faculty, institution or policy, and stakeholders [6]. Some of the barriers identified in the study were limited classroom time and space, limited guidance on how to integrate LGBT topics, limited knowledge of LGBT population, uncomfortable or opposes teaching the topic, social pressures from institutions including religious affiliations, and accreditation is not required [5]. This paucity of evidence exemplified the need for further research in the area of cultural competency of nursing faculty on LGBT issues.

\section{Conceptual Framework}

Campinha-Bacote's Process of Cultural Competence in the Delivery of Healthcare Services was used to guide this study [10]. Cultural competence was defined by Campinha-Bacote as, "the process in which the nurse continuously strives to achieve the ability and availability to effectively work within the cultural context of a client (individual, family, community)" [10]. The model assumed that cultural competence is a continuous process that involves integration of cultural awareness, cultural knowledge, cultural skill, cultural encounter, and cultural desire. Further, cultural competence involved cultural awareness, which requires self-examination of one's biases, cultural knowledge, and cultural skills when conducting assessment, cultural encounters, and cultural desire to engage in the process [10].

Cultural awareness was defined as "examination and in-depth exploration of one's own cultural and professional background", and cultural encounter was the "process that encourages the health care provider to directly engage in cross-cultural interactions

Nur Primary Care, 2018 with clients from culturally diverse backgrounds" [10]. Cultural knowledge was "the process of seeking and obtaining a sound educational foundation about diverse culture and ethnic groups" whereas cultural skill was the "ability to collect relevant cultural data regarding the client's presenting problem as well as accurately performing a culturally based physical assessment" [10]. Lastly, cultural desire was "the motivation of the health care provider to want to; rather than have to, engage in the process of becoming culturally aware, culturally knowledgeable, culturally skillful, and familiar with cultural encounters" [10]. In this study, this theory was chosen because, for nursing faculty to be able to teach students on LGBT care, they must fully embrace the five constructs of cultural competency.

\section{Methods}

A prospective and correlational study design was used. After Institutional Review Board approval was obtained, 80 survey packets were distributed to both full-time and part-time nursing faculty, including adjuncts and clinical instructors, teaching in the nursing programs at two regional universities. The list of the nursing faculty was obtained from the universities' websites. A sample of at least 30 nursing faculty is desirable to ensure a power of $80 \%$ to detect a moderate correlation at the .05 level of significance. Faculty participation in the study was anonymous and voluntary. Study packets contained information sheet, demographic worksheet, and the four surveys.

\section{Instruments}

\section{Attitudes}

The Attitudes toward Lesbians, Gay Men and Bisexual (ATLGB) Scale [11], and the Attitudes toward Transgender Individual (ATTI) scale [12], were used to evaluate attitudes toward LGBT individuals. The ATLGB is a 13-item survey on a 4-point Likert scale (e.g, 1- strongly disagrees, 4 strongly agree). The possible range of scores for this scale was 13 (mostly positive attitude) to 52 (mostly negative attitudes). The original ATLG subscales have high internal consistency of $\alpha>.80$ for most non-student adult samples. ATLG also has established discriminant validity [11].

The ATTI is a 20-item self-report measure that evaluates level of transphobia. Each item is a 5-point Likert scale ( $1=$ strongly agree, $2=$ agree, $3=$ neither agree or disagree, 4-disagree, and 5-strongly disagree). Higher scores denote greater tolerance toward transgendered individuals. This instrument was shown to have high internal consistency (Cronbach's $\alpha=.95$ ). ATTI moderately correlated with Genderism and Transphobia Scale $(r=-.29$ and $r$ $=-.38)$ and Acceptance of Stereotyping Questionnaire $(r=-.38$ and $\mathrm{r}=-.32$ ). Discriminant validity was assessed by computing correlation coefficient between ATTI and other measures that are theoretically unrelated to attitudes towards transgendered individuals. Permission is not required to use this survey [12].

Knowledge

The 15-item true/false LGBT Knowledge Questionnaire by [11], was used to measure nursing faculty's knowledge of LGBT. The instrument reported suboptimal reliability (Cronbach $\alpha=0.54$ ). 
Permission to use this instrument was obtained from the authors.

Cultural Competency

The Inventory for Assessing the Process of Cultural Competence among Healthcare Professional - Revised (IAPCC-R) by [10], was used to assess cultural competence of nursing faculty. The IAPCC-R is a 25-item survey on a 4-point Likert scale that measures the five constructs of cultural competence - cultural desire, cultural awareness, cultural knowledge, cultural skills, and cultural encounter. Scores ranged from 25-100, with the higher the score, the higher their level of cultural competence. The level of cultural competence based on IAPCC-R scores were: 91-100 is culturally proficient; $75-90$ is culturally competent; $51-74$ is culturally aware, and $25-50$ - is culturally incompetent. The instrument has a reliability of Cronbach's $\alpha$ of 0.780 for total scores, which is considered acceptable. Permission to use this instrument was obtained from Dr. Campinha-Bacote.

\section{Data Analysis}

Statistical Package for the Social Sciences (SPSS) Version 24 statistical software was used to perform statistical analysis. Means, frequencies, percentages, standard deviations, and chisquare will be used to measure knowledge, attitudes, and cultural competencies of nursing faculty. Analysis of variance (ANOVA) was performed to assess relationships among variables.

\section{Results}

Demographic Characteristics

Thirty-five returned the survey (44\% response rate). The cohort consisted of $94 \%$ females, mean age of $51.5( \pm 12.5)$ years, majority were married and heterosexuals, and with $13 \pm 12$ years of teaching experience. Majority of the nursing faculty taught in the undergraduate program, whereas $20 \%$ taught in both undergraduate and graduate programs. Table 1 presents the overall sociodemographic profile of the cohort.

\begin{tabular}{|c|c|c|c|}
\hline $\begin{array}{c}\text { Demographic } \\
\text { Characteristics }\end{array}$ & & & $\begin{array}{c}\text { Demographic } \\
\text { Characteristics }\end{array}$ \\
\hline Age & $\begin{array}{c}\text { Mean }-51.5 \\
( \pm 12.5) \text { years }\end{array}$ & $\begin{array}{c}\text { Sexual orientation } \\
\text {-Heterosexual }\end{array}$ & $94 \%(33)$ \\
\hline Gender & $\%(\mathrm{n})$ & & \\
\hline Male & $6 \%(2)$ & Homosexual & $3 \%(1)$ \\
\hline Female & $94 \%(33)$ & Prefers not to answer & $3 \%(1)$ \\
\hline Race & & Highest degree earned & \\
\hline Asian & $5 \%(2)$ & Bachelor's degree & $12 \%(4)$ \\
\hline $\begin{array}{c}\text { Blacks/African- } \\
\text { American }\end{array}$ & $29 \%(10)$ & Master's degree & $34 \%(12)$ \\
\cline { 2 - 4 } Caucasian/White & $60 \%(21)$ & Doctoral degree & $54 \%(19)$ \\
\hline Multi-racial & $3 \%(1)$ & Program teaching & \\
\hline Missing data & $3 \%(1)$ & Undergraduate & $66 \%(23)$ \\
\hline Marital status & & & $14 \%(5)$ \\
\hline Single & $11 \%(4)$ & Graduate & $20 \%(7)$ \\
\hline Married & $69 \%(24)$ & Both & \\
\hline Divorced/separated & $14 \%(5)$ & Teaching appointment & \\
\hline & & & \\
\hline
\end{tabular}

Nur Primary Care, 2018

\begin{tabular}{|c|c|c|c|}
\hline In a relationship & $6 \%(2)$ & Full-time & $66 \%(22)$ \\
\hline Religious affiliation & $\begin{array}{c}\text { Part-time (including } \\
\text { adjunct/lecturers) }\end{array}$ & $34 \%(13)$ \\
\hline Yes & $89 \%(31)$ & Years of teaching & $\begin{array}{c}\text { Mean }-13 \\
( \pm 12) \text { years }\end{array}$ \\
\hline No & $11 \%(4)$ & ynnnnn
\end{tabular}

Table 1: Demographic Characteristics of Cohort $(n=35)$.

Knowledge

The mean score based on individual grades was $88 \%( \pm 13.6$, range of $47 \%-100 \%)$. Thirteen (37\%) nursing faculty answered all questions correctly, and $20 \%$ of nursing faculty received a score of less than $75 \%$. Reliability of this instrument in this study was calculated as Cronbach á $=0.673$, which remains below acceptable range but increasing.

\section{Attitudes}

The mean score of ATTI was $75.9( \pm 11.8)$. The minimum score was 49 and the highest score was 91 . Forty percent of the nursing faculty scored between $51-75$, and $57 \%$ scored over 76 . The mean score on the ATLGB $(n=32)$ was $43.06 \pm 18.6$ (range was 1352 ), indicating a negative attitudes towards homosexuality. Three faculty members only completed half of the survey, therefore their responses were excluded in this analysis.

\section{Cultural Competency}

The mean score on the IAPCC-R survey was $53( \pm 8)$. The minimum score was 36 and highest score was 67 . This result was interpreted as nursing faculty were culturally aware of the LGBT population. Further, of the five constructs of cultural competency, cultural desire had the lowest score (Table 2).

\begin{tabular}{|c|c|c|}
\hline Constructs of Cultural Competence & Mean Scores & Range (L-H) \\
\hline Cultural Awareness & $10.7( \pm 2.3)$ & $6-16$ \\
\hline Cultural Knowledge & $12.9( \pm 2.6)$ & $8-17$ \\
\hline Cultural Skills & $11.1( \pm 2.2)$ & $6-15$ \\
\hline Cultural Encounters & $11.1( \pm 2.5)$ & $5-15$ \\
\hline Cultural Desire & $7.44( \pm 2.1)$ & $5-12$ \\
\hline
\end{tabular}

Table 2: Scores on Constructs of Cultural Competency.

\section{Relationship among Variables}

The present study showed no significant correlations between IAPCC-R and knowledge of LGBT, and between IAPCC-R and attitudes towards LGBT individuals. There was a significant negative correlation found between years of teaching experience and IAPCC-R $(r=-.403, p=0.022)$.

\section{Discussion}

There were several significant findings noted in this present study. First, a major finding in the present study was that nursing faculty members from two regional universities were culturally aware, but not culturally proficient with the LGBT population. The present study was one of the first studies, if not the first, to quantitatively examine cultural competence of nursing faculty.

Second, the study noted that nursing faculty has negative attitudes 
towards the LGBT population. This is inconsistent with previous study by [9], who noted that nurse educators have positive attitudes toward homosexuality. This study, however, is consistent with the integrative review of the literature [13], who found evidence of negative attitudes among nurses toward LGBT patients.

Third, this study also found that knowledge was one of the highest scores among the five cultural competence construct. This was supported by the results on the knowledge questionnaire, in which $80 \%$ of nursing faculty scored $80 \%$ and over, and $35 \%$ of faculty scored $100 \%$. This finding was inconsistent with Lim et al.'s study who found that nursing faculty has limited knowledge of LGBT [6].

Fourth finding is that a significant negative correlation between cultural competence and years of teaching experience, meaning the more years of teaching experience the lower their cultural competence. However, there was no correlation noted between years of experience and the five cultural competence constructs, this needs to be researched further in a larger sample size.

\section{Conclusion}

This present study shows that nursing faculty is not culturally competent and has negative attitudes towards the LGBT population. In addition, years of teaching experience correlates with cultural competence. To our knowledge, this study was the first study to quantitatively examine cultural competence of nursing faculty on LGBT. This suggested a dearth of literature related to cultural competence of nursing faculty related to LGBT care.

The study acknowledges some limitations. Sample size is small. Generalizability is limited because nursing faculty from only two regional universities were surveyed. The present study did not include the term queer (Q) because at the time of study development, the Q in LGBTQ had not been used or added.

\section{Implications to Nursing}

Findings from this study have substantial impact in nursing research. These provided reference data as to the current cultural competence of nursing faculty. Future research is needed using a larger sample size. It may be significant to perform a follow up study examining the five constructs of cultural competency and their correlation with other variables. At the same time, the Q in LGBTQ needs to be included in further research on cultural competence. Lastly, further study is needed to determine the significance of years of teaching experience with regards to cultural competence of the LGBT population. This study presented a paucity of evidence that exemplifies an urgent need for LGBT cultural competence research among health care educators.

\section{References}

1. Pew Research Center. The number of Americans identifying as LGBT is rising. 2017. http://www.pewresearch.org/facttank/2017/06/13/5-key-findings-about-lgbt-americans/ft_1706-12 lgbtamericans rise/

2. Gates GJ. LGBT Demographics Comparisons among population-based surveys. Williams Institute, UCLA School of Law. 2014.

3. Institute of Medicine The health of lesbian, gay, bisexual and transgender people, Building a foundation for better understanding. Washington DC The National Academies Press. 2011.

4. Jeffreys MR, Dogan E. Evaluating the influence of cultural competence education on students' transcultural self-efficacy perceptions. Journal of transcultural nursing. 2012; 23: 188197.

5. Lim F, Brown JV, Jones BH. Lesbian, gay, bisexual, and transgender health: fundamentals for nursing education. Journal of nursing education. 2013; 52: 198-203.

6. Lim F, Johnson M, Eliason M. A national survey of faculty knowledge, experience and readiness for teaching lesbians, gay, bisexual, and transgender health in baccalaureate nursing program. Nursing education perspectives. 2015; 38: 144-152.

7. Obedin-Maliver J, Goldsmith ES, Stewart L, et al. Lesbian, gay, bisexual, and transgender-related content in undergraduate medical education. Journal of the American Medical Association. 2011; 306: 971-977.

8. Sekoni AO, Gale NK, Manga-Atangana B, et al. The effects of educational curricula and training on LGBT-specific health issues for healthcare students and professionals: A mixedmethod systematic review. Journal of the International AIDS Society, 2017; 20(1), 216-224. Retrieved from: https:// onlinelibrary.wiley.com/doi/abs/10.7448/IAS.20.1.21624

9. Sirota T. Attitudes among nurse educators toward homosexuality. Journal of nursing education. 2013; 52: 219227.

10. Campinha-Bacote J. The process of cultural competence in the delivery of healthcare services a model of care. Journal of transcultural nursing. 2002; 13: 181-184.

11. Strong KL, Folse VN. Assessing undergraduate nursing students' knowledge, attitudes and cultural competence in caring for LGBT patients. Journal of nursing education. 2015; 54: 45-49.

12. Walsh SE, Ngamake ST, Francisco J, et al. The attitudes toward transgender individuals scale psychometric properties. Archives of sexual behavior. 2012; 41: 1283-1291.

13. Dorsen C. An integrative review of nurse attitudes towards LGBT patients. Canadian Journal of Nursing Research. 2012; 44: $18-43$.

(C) 2018 Caboral-Stevens M. This article is distributed under the terms of the Creative Commons Attribution 4.0 International License 